\title{
Influence of quorum sensing signal molecules on biofilm formation in Proteus mirabilis 018
}

\author{
Dorota Stankowska • Grzegorz Czerwonka • \\ Sylwia Rozalska $\cdot$ Michalina Grosicka . \\ Jaroslaw Dziadek • Wieslaw Kaca
}

Received: 22 June 2011 / Accepted: 6 December 2011 /Published online: 24 December 2011

(C) The Author(s) 2011. This article is published with open access at Springerlink.com

\begin{abstract}
The influence of basis of quorum sensing molecules on Proteus strains is much less known as compared to Pseudomonas or Escherichia. We have previously shown that a series of acylated homoserine lactones (acyl-HSL) does not influence the ureolytic, proteolytic, or hemolytic abilities, and that the swarming motility of Proteus mirabilis rods is strain specific. The aim of the presented study was to find out if the presence of a series of acyl-HSL influences biofilm formation of $P$. mirabilis laboratory strain belonging to $\mathrm{O} 18$ serogroup. This serogroup is characterized by the presence of a unique non-carbohydrate component, namely phosphocholine. Escherichia coli and P. mirabilis $\mathrm{O} 18$ strains used in this work contains cloned plasmids encoding fluorescent protein genes with constitutive gene expression. In mixed biofilms in stationary and continuous flow conditions, P. mirabilis $\mathrm{O} 18$ overgrow whole culture. P. mirabilis $\mathrm{O} 18$ strain has genetically proved a presence of AI-2 quorum sensing system. Differences in biofilm structure were observed depending on the biofilm type and culture methods. From tested acylated homoserine lactones (BHL, HHL, OHL, DHL, dDHL, tDHL), a significant influence
\end{abstract}

\footnotetext{
D. Stankowska $\cdot$ S. Rozalska

Institute of Microbiology, Immunology and Biotechnology,

University of Lodz,

Lodz, Poland

G. Czerwonka $(\bowtie) \cdot$ M. Grosicka $\cdot$ W. Kaca

Department of Microbiology, Institute of Biology,

Jan Kochanowski University in Kielce,

Kielce, Poland

e-mail: gczerwonka@ujk.edu.pl

J. Dziadek

Institute of Medical Biology, Polish Academy of Sciences,

Lodz, Poland
}

had BHL on thickness, structure, and the amount of exopolysaccharides produced by biofilms formed by $P$. mirabilis O18 pDsRed $_{2}$.

\section{Introduction}

Urinary tract infections (UTIs) are among the most frequently occurring human bacterial infections, accounting for about $20 \%$ of all infections acquired outside the hospital. Almost $90 \%$ of UTIs are ascending, with bacteria gaining access to the urinary tract via the urethra to the bladder and then to the upper part of the urinary tract (Heydorn et al. 2000; Hryniewicz et al. 2001). The organism causing a UTI usually originates from the patient's own bowel flora. The most frequent etiological agents causing UTIs are Gram-negative bacteria belonging to the Enterobacteriaceae family (Gupta et al. 2001; Stickler et al. 2003). Proteus mirabilis is one of the most common causes of UTIs in individuals with longterm indwelling catheters or complicated UTIs and of bacteremia among the elderly (Liaw et al. 2004; Sosa and Zunino 2009; Stickler et al. 2003). Bacterial virulence factors are regulated by quorum-sensing molecules which are derivatives of serine substituted by a fatty acid, i.e., acylated homoserine lactones, abbreviated as acyl-HSLs (Henke and Bassler 2004; Li et al. 2005; Lucas et al 2000; Soto et al. 2002; Wang et al. 2004; Williams et al. 2000). The quorum sensing mechanism involves two types of autoinducers: AI1 based on homoserine lactone and AI-2 based on other molecules. The majority of signal substances in Gramnegative bacteria are substituted by fatty acid derivatives of acyl-HSL (AI-1). There is no evidence that quorum sensing receptors and AI-1 signal molecules are associated with swarming motility in P. mirabilis (Belas et al. 1998). An essential enzyme for AI-2 type is the LuxS molecule 
coded by $\operatorname{lu} x S$ gene, which has $S$-ribosylhomocysteine lyase activity. The product 4,5-dihydroxypentan-2,3-dione spontaneously cyclizes and combines with borate to form an AI2 signal molecule (Schauder et al. 2001). Previous studies proved the presence of AI-2 type quorum sensing in $P$. mirabilis (Schneider et al. 2002). A luxS mutation in $P$. mirabilis showed no effect on growth, the production of urease, protease or hemolysin, swimming motility and behavior, swarmer cell differentiation, swarming behavior, and biofilm formation (Schneider et al. 2002). AI-2 quorum sensing is an important pathogenic factor present in species other than P. mirabilis. It is also widespread in the intestinal microflora of animals and humans (Schneider et al. 2002). As of today, the complete sequences of two P. mirabilis strains, HI4320 and ATCC 29906, are known. Both strains contain the $\operatorname{luxS}$ gene encoding S-ribosylhomocysteine lyase, which takes part in the quorum sensing communication process. Also in another P. mirabilis strain, BB2000, RsbA membrane sensor proteins were found. They may play an important role in receiving density signals, similarly to the LuxQ protein in Vibrio harveyi (Schneider et al. 2002). The influence of basis of quorum sensing molecules on Proteus strains is much less known as compared to Pseudomonas or Escherichia. In our previous work, we showed that a series of HSL derivatives did not influence the ureolytic, proteolytic, or hemolytic abilities, and that the swarming motility of $P$. mirabilis rods was strain specific. $P$. mirabilis with a negatively charged $O$-polysaccharide demonstrated strong ureolytic and proteolytic properties and a greater migration speed on solid media. There was no influence of acyl-HSLs on the process of urea decomposition, but they inhibited protease activity in five P. mirabilis strains. $N$-butanoyl-L-homoserine lactone accelerated the migration speed of the tested P. mirabilis strains. Acetylated homoserine lactone derivatives modified the expression of only some virulence factors of $P$. mirabilis strains (Stankowska et al. 2008). In our previous study, we demonstrated that differences in the structure of the $O$-polysaccharide part of the LPS influences the biological activity of $P$. mirabilis strains (Chromek et al. 2005). P. mirabilis $\mathrm{O} 18$ was biologically more active than P. mirabilis O3 (S1959) LPS. P. mirabilis O18 LPS is characterized by a phosphocholine substituent in the $O$ polysaccharide part, whereas $P$. mirabilis $\mathrm{S} 1959$ possesses a lysine residue. Apart from the biological activity of LPS, other virulence factors of $P$. mirabilis $\mathrm{O} 3$ and P. mirabilis $\mathrm{O} 18$ strains were not examined (Chromek et al. 2005). Biofilm formation was not studied in our previous work. The aim of the presented study was to find out if the presence of a series of acyl-HSL would influence biofilm formation by $P$. mirabilis O18 and Escherichia coli laboratory strains. P. mirabilis strain belongs to $\mathrm{O} 18$ serogroup and is characterized by the presence of a unique non-carbohydrate component, namely phosphocholine.

\section{Materials and methods}

Bacterial strains

P. mirabilis O18 laboratory strains PrK 34/57, O10 PrK 20/ 57 was obtained from the Czech National Collection of Type Cultures, P. mirabilis S1959 was obtained from the Institute of Microbiology and Immunology, University of Lodz, Poland, while the P. mirabilis 1784 (O18) clinical isolate was from the Swietokrzyskie Oncology Center in Kielce, Poland.

\section{P. mirabilis $\mathrm{O} 18 \mathrm{pDsRed}_{2}$ and E. coli $\mathrm{pCGJ}$ strains}

Marker genes such as $g f p$ or $d s R e d$ coding fluorescent proteins (GFP, DsRed) are widely used for visualization bacterial cells (Wielbo et al. 2010). To obtain a P. mirabilis O18 strain expressing constitutively DsRed $_{2}$ protein an ampicillin-sensitive $P$. mirabilis $\mathrm{O} 18$ was electroporated with a $\mathrm{pDsRed}_{2}$ prokaryotic expression vector that encodes $\operatorname{DsRed}_{2}$ containing pUC plasmid replication origin (Clontech). The transformants were screened on LB agar with ampicillin. Plasmids were isolated from randomly selected colonies. Isolated plasmids were checked on $1 \%$ agarose gel by electrophoresis with control $\mathrm{pDsRed}_{2}$ DNA. This strain was confirmed by appearance of red fluorescence. Ten passages of the obtained P. mirabilis $018 \mathrm{pDsRed}_{2}$ strain showed stable plasmid replication. For the generation of the $\boldsymbol{E}$. coli fluorescent strain expressing the $\boldsymbol{G F P}$ protein, the $g f p$ gene was amplified by PCR using the primers with added restriction sites GFP-BamHI-F (5'-CGGGATCCCAT GAGTAAAGGA GAAGAAC-3') and GFP-EcoRI-R (5'GGAATTCTTATTTGTATAGTTCATCC-3') from pJFR8 plasmid. An amplicon was eluted from agarose gel and ligated into pGEM-T (Promega) vector. E. coli TOP 10 (Invitrogen) was transformed with a ligation mixture. Transformants selection was performed on an LB medium supplemented with ampicillin, IPTG (isopropyl $\beta$-D-1thiogalactopyranoside) and X-Gal (5-bromo-4-chloro-3indolyl-beta-D-galactopyranoside). A plasmid (named pGEM-GFP) was isolated from chosen transformants and was separated on $1 \%$ agarose gel where a plasmid DNA of pGEM-T was used as a control. The next step was a restriction analysis of obtained plasmid DNA with a EcoRI restriction enzyme. A selected clone (with proper lengths of restriction fragments) was digested with $B a m \mathrm{HI}$ and EcoRI restriction enzymes. A 750-base pair (bp) fragment was eluted from gel and was ligated with the DNA of the pECFP vector previously digested with the same enzymes. $E$. coli TOP 10 was transformed with the ligation mixture. Transformant selection was performed on LB medium supplemented with ampicillin. A plasmid DNA was isolated from the selected transformants and was separated on $1 \%$ agarose 
gel where pGEM-GFP plasmid DNA was a control. The resulting plasmid was named pCG. The pCG plasmid DNA was isolated from the selected transformants and was separated by gel electrophoresis on $1 \%$ agarose gel, pJFR8 plasmid was used as a source of kanamycin-resistance cassette. A 2,116-bp ScaI-EcoRI fragment containing aph was PCR-amplified from E.coli-pJFR8 and was cloned into the ScaI-EcoRI sites of pCG to construct pCGJ. The E. coli strain showed stable plasmid replication and produced a GFP protein.

Plasmids used in work

pJFR8 - modified pCR2.1TOPO vector (4.5 kilobase pair $(\mathrm{kb})$ ) coding GFP protein and kanamycin resistance gene. Obtained from the Institute of Medical Biology, Polish Academy of Sciences, Lodz, Poland.

pECFP - $3.4 \mathrm{~kb}$ plasmid vector coding cyan variant of GFP tag and ampicillin resistance (Clonetech)

Acylated homoserine lactones

Acylated homoserine lactones (acyl-HSLs) used in this work are presented in Table 1. Acyl-HSLs were added to growing culture in a concentration of $10 \mathrm{nmol} / \mathrm{L}$. Other concentrations of acyl-HSLs were examined in previous studies, and $10 \mathrm{nmol} / \mathrm{L}$ concentrations were selected as optimal for biofilm tests.

Identification of the quoum sensing marker genes

Identification of the luxS gene was performed by the amplification of DNA fragments and restriction analysis. Primers were designed with Primer-BLAST based on the genome sequence published for $P$. mirabilis HI4320. The sequence of the forward primer (luxsF) was 5'-GTATGTCTG CACCTGCGGTA-3' and that of the reverse primer (luxsR)

Table 1 Acylated homoserine lactones (Fluka)

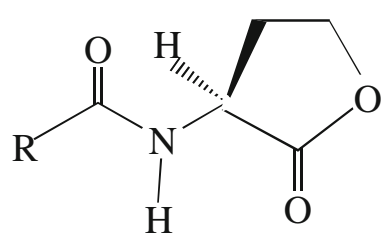

\begin{tabular}{lll}
\hline Acronyms & Full name & $\mathrm{R}$ \\
\hline BHL & $N$-butanoyl homoserine lactone & $\mathrm{CH} 3(\mathrm{CH}) 2$ \\
HHL & $N$-hexanoyl homoserine lactone & $\mathrm{CH} 3(\mathrm{CH}) 4$ \\
OHL & $N$-octanoyl homoserine lactone & $\mathrm{CH} 3(\mathrm{CH}) 6$ \\
DHL & $N$-decanoyl homoserine lactone & $\mathrm{CH} 3(\mathrm{CH}) 8$ \\
dDHL & $N$-dodecanoyl homoserine lactone & $\mathrm{CH} 3(\mathrm{CH}) 10$ \\
tDHL & $N$-tetradecanoyl homoserine lactone & $\mathrm{CH} 3(\mathrm{CH}) 12$ \\
\hline
\end{tabular}

was 5'-TTTGAGTTTGTCTTCTGGTAGTGC-3'. The length of the product was $464 \mathrm{bp}$ with one restriction site for EcoRI. The template for PCR was chromosomal DNA isolated from P. mirabilis strains PrK 34/57 (O18) and PrK 20/57 (O10). PCR protocol contains steps: initial denaturation in $95^{\circ} \mathrm{C}$ for $3 \mathrm{~min}, 30 \times$ cycles; denaturation in $95^{\circ} \mathrm{C}$ for $90 \mathrm{~s}$; annealing in $56.8^{\circ} \mathrm{C}$ for $60 \mathrm{~s}$; and extending in $72^{\circ} \mathrm{C}$ for $60 \mathrm{~s}$, the final extending step is done in $72^{\circ} \mathrm{C}$ which lasts for $10 \mathrm{~min}$. PCR reaction was made to amplify a homolog of spnR and spnI genes from P. mirabilis strain PrK34/57 (O18), 1784 and S1959 genomic DNA by PCR using primers designed by Zhu et al. (2008). The sequence of primers for spnI gene was 5'-CTTGAACTGTTT GACGTCAGC-3' and 5'-AGCGGCCAGGTAATA ACTGA-3' forward and reverse, respectively. And for the spnR gene, the forward primer was 5'-GCCTTCAATGA AAATCAGACC-3' and 5'-TGTCGCTGTGATAA GCTCCA-3' for the reverse primer. The expected product size was 627 and $744 \mathrm{bp}$ for $\mathrm{spnI}$ and $\mathrm{spnR}$, respectively.

In silico analysis

Calculations were performed with Vector NTI Suite 7 and the GenBank database.

Thin layer chromatography

Extraction of signal substances was performed with ethyl acetate both from supernatant and solid medium according to the method given by Shaw et al. (1997). Samples were separated on silica gel 60 F254 with acetone/methylene chloride $(2: 8, v / v)$ solvent or methanol/methylene chloride $(1: 9, v / v)$ for preparative thin layer chromatography (TLC) purpose. The identification of fractions was performed with UV light and dying with potassium permanganate. Desired spots were isolated by scraping from the TLC plate and extracted with subsequent washes of $10 \%$ methanol in $\mathrm{H}_{2} \mathrm{O}$, dried, and re-suspended in ethyl acetate. Acyl-HSL mixture contained five selected lactones.

Biofilm formation

Biofilms were formed in $37^{\circ} \mathrm{C}$ in two different sets: in stationary conditions and in continuous flow chambers. Growth medium was artificial urine consisting of M9 minimal medium $\left(\mathrm{Na}_{2} \mathrm{HPO}_{4}, 42.3 \mathrm{mmol} / \mathrm{L} ; \mathrm{KH}_{2} \mathrm{PO}_{4}, 22 \mathrm{mmol} /\right.$ $\mathrm{L} ; \mathrm{NH}_{4} \mathrm{Cl}, 8.6 \mathrm{mmol} / \mathrm{L}$; glucose, $12.2 \mathrm{mmol} / \mathrm{L}$; casein hydrolysate, $0.005 \%$; thiamine, $0.005 \% ; \mathrm{MgCl}_{2}, 0.1 \mathrm{mmol} / \mathrm{L}$; $\mathrm{pH}=8.0$ ) supplemented with $0.01 \%$ urea. Biofilm formation process lasted 4 days. A continuous flow of the medium was performed at a speed of $0.2 \mathrm{~mL} / \mathrm{min}$ on a peristaltic pump. Flow conditions assays were performed on FC 71-BST chambers (BioSurface Technologies Corp.). Biofilm 
presence and parameters were calculated with the COMSTAT software by Heydorn et al. (2000). Statistical analyses were performed on a SigmaStat software (SPSS, Inc., IL). The features of the biofilms were analyzed by Tukey's multiple comparisons test. A determination of the amount of exopolysaccharides in the biofilm was carried out in accordance with the method of Hamilton et al. (2003).

\section{Results}

In silico analysis of quorum sensing encoding molecules

In silico analysis with blast algorithms proved that there is no sequence similar to the luxP $V$. fischeri ES114 sequence in two sequenced P. mirabilis HI4320 and ATCC 29906. Also, the peptide sequence of LuxP has no analogs in the $P$. mirabilis databases. Similar results were obtained for the luxR gene and its product. Another comparison of the lux$C D A B E$ operon from Photorhabdus luminescens subsp. laumondii strain TT01 with P. mirabilis completed genomes showed no significant homology. A similar situation holds for two LuxI-type proteins EsaI and LasI which catalyze the synthesis of 3-oxo-C6-homoserine lactone (3OC6-HL) and 3-oxo-C12-homoserine lactone (3OC12-HL) (Nasser and Reverchon 2007). A comparison of the P. mirabilis HI4320 luxS sequence with the Megablast algorithm to the genomes of other bacteria revealed a high similarity to the Shewanella luxS sequence. Other genetic elements involved in the AI-1 quorum sensing mechanism were not found in the published genome sequences of $P$. mirabilis.

\section{Identification of the luxS gene}

The PCR reaction resulted in a 464-bp amplicon, which corresponds to the P. mirabilis HI4320 luxS gene. The cleavage of the amplified fragment resulted in 121- and 343-bp products and confirmed that the amplified products are $l u x S$ gene fragments (Fig. 1). Amplification of spnI and spnR genes did not succeed (data not shown).

\section{Identification of signal substances in P. mirabilis strains}

We attempted to identify acyl-HSL derivatives in P. mirabilis cultures. Twelve of the P. mirabilis strains used differ in their O-antigens structures. TLC was applied to investigate if acyl-HSLs were present in cell-free supernatants from $P$. mirabilis cultures. The TLC separation of acylated homoserine lactones (BHL, HHL, DHL, OHL, dDHL) from the mixture was successful. The separation was performed based on the differences in the chemical structure and polarity of the lactones. Extracts obtained with ethylene acetate were characterized with the presence of substances whose

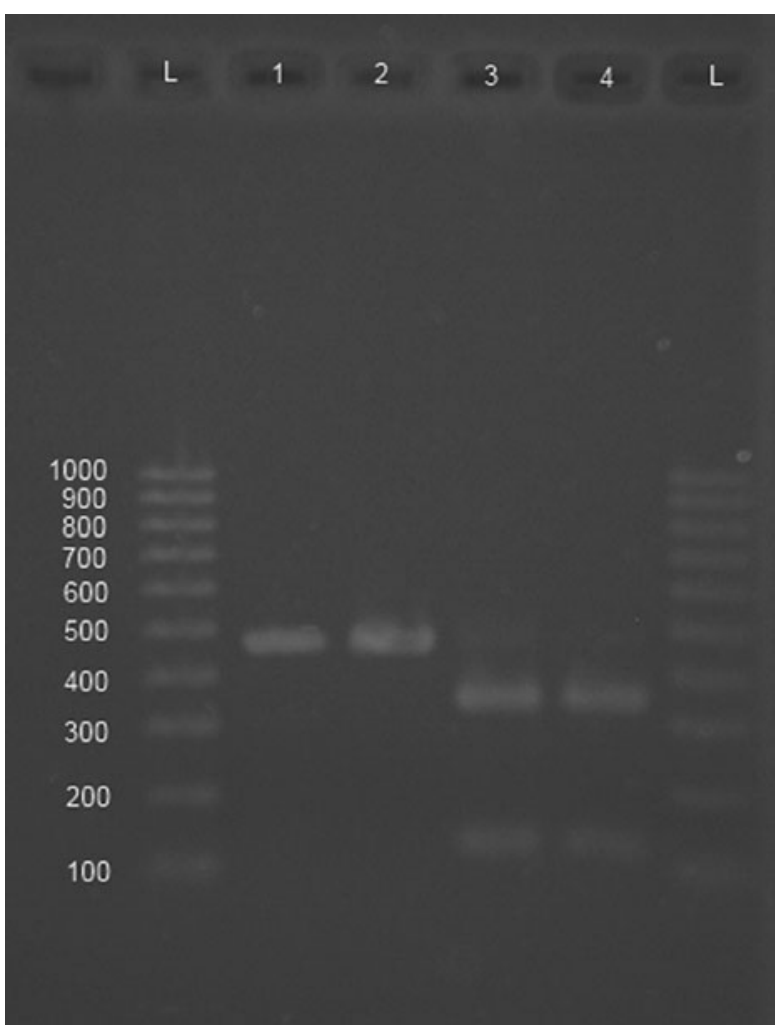

Fig. 1 Amplification of luxS coding element (row 1 PrK 34/57; row 2 PrK 20/57) and restriction analysis (row 3 Prk 34/57; row 4 PrK 20/57) with EcoRI restriction enzyme, ladder 100 bp (Fermentas)

migration Rf was identical to that of the HHL control sample $\left(R_{f}=0.46\right)$. To confirm that the obtained isolate from P. mirabilis $\mathrm{O} 18$ is the homoserine lactone derivative, the corresponding spot was extracted and analyzed by the GC-MS method. Retention times were 27.6 and $28.9 \mathrm{~s}$ - the same as in a parallel run of the HHL standard (data not shown). An analysis of the ion fragmentation revealed typically of a homoserine lactone ion $102.11 \mathrm{~m} / \mathrm{e}$ similar to that observed by Shaw et al. (1997).

The influence of acyl-HSL derivatives on biofilm formation by $P$. mirabilis $\mathrm{O} 18$

Biofilm formation was assessed in the laboratory P. mirabilis strain expressing constitutively $\operatorname{DsRed}_{2}$ protein (P. mirabilis $\mathrm{O} 18 \mathrm{pDsRed}_{2}$.). Biofilms formed by the laboratory strain P. mirabilis $\mathrm{O} 18 \mathrm{pDsRed}_{2}$ differ in structure depending on the type of culture method used for the biofilm formation. Bacterial cells grown in chambers without constant medium flow produced biofilms with a small amount of extracellular mucous. In contrast, cultures in chambers with continuous flow of artificial urine produced biofilms with significant amounts of extracellular mucus. To quantify biofilm composition, calculations were done with the aid of 
the COMSTAT software (Heydorn et al. 2000). A continuous flow of the medium at a speed of about $0.2 \mathrm{~mL} / \mathrm{min}$ resulted in increased carbohydrate production. After 7 days of cultivation in the stationary chamber, the biofilm volume was ten times lower $\left(0.025 \pm 0.01 \mu \mathrm{m}^{3} / \mu \mathrm{m}^{2}\right)$ than in the continuous flow chamber $\left(0.29 \pm 0.028 \mu \mathrm{m}^{3} / \mu \mathrm{m}^{2}\right)$. The area covered by biofilm differed significantly depending on the method of cultivation used. In stationary cultures, the area of the chamber covered by biofilm was only $0.73 \%$, while in the flow chamber the area covered reached $6.23 \%$. Differences were noticed also in the maximal biofilm thickness $(p<0.02$, paired $t$ test). In the stationary chamber, the maximal thickness was $7.2 \pm 1.15 \mu \mathrm{m}$ while in the flow chamber it was $100 \pm 0.98 \mu \mathrm{m}$. In the next experiment, biofilms were formed by mixed cultures of $P$. mirabilis $018 \mathrm{pDsRed}_{2}$ and $E$. coli pCGJ strains with green fluorescence proteins encoded and expressed. Biofilms were formed under different conditions: in stationary chambers and in continuous artificial urine flow chambers. As in previous assays, under flow conditions the formed biofilm had different structure from that formed in the stationary chamber. In the stationary culture method, mixed P. mirabilis $\mathrm{O} 18 \mathrm{pDsRed}_{2}$ and E. coli pCGJ biofilms produce much fewer mushroom-like structures than in flow chamber cultures. Both species were able to form microcolonies; however, majority of them were formed by $P$. mirabilis $\mathrm{O} 18 \mathrm{pDsRed}_{2}$ alone. The thickness of the mixed biofilm in the stationary chamber was $4.8 \pm$ $0.98 \mu \mathrm{m}$, while in the flow chamber the thickness was $9.1 \pm$ $2.86 \mu \mathrm{m}$ after $96 \mathrm{~h}$ of cultivation, with the difference being statistically significant $(p<0.026$, paired $t$ test). Biofilm formed under flow conditions had a more complex structure. An increased expression of exopolysaccharides compared to the control was also observed. The amount of polysaccharides produced in the mixed biofilm was higher and statistically different compared to single strain biofilms formed by P. mirabilis $(p<0.027$, paired $t$ test $)$ and E. coli $(p<0.086$, paired $t$ test). To examine the influence of acylated homoserine lactones on biofilms formed by P. mirabilis $\mathrm{O} 18$ $\operatorname{DspRed}_{2}$, the thickness of the biofilms was compared. Two types of cultures were used, those grown in stationary and continuous flow chambers. Under stationary conditions, after 7 days of incubation an increased thickness of biofilms in the presence of homoserine lactones was observed. The biofilm formed after treatment with DHL was 6.6 \pm 2.158 $\mu \mathrm{m}$ thick. The thickest biofilm resulted after treatment with BHL, 11.6 $\pm 2.993 \mu \mathrm{m}$. This increase in biofilm thickness is statistically significant as compared to the control $(p<0.002$, Tukey's statistic). A similar effect was observed under continuous flow conditions for biofilm formed by P. mirabilis O18 $\mathrm{pDsRed}_{2}$. Biofilm thickness varied between $9 \pm$ $0.02 \mu \mathrm{m}$ with HHL treatment and $14.85 \pm 1.479 \mu \mathrm{m}$ with DHL treatment. DHL enhanced the thickness in a statistically significant manner ( $p<0.002$, Tukey's statistic) compared to the control. To detect time-depended formation of biofilm by the $P$. mirabilis $\mathrm{O} 18 \mathrm{pDsRed}_{2}$ strain treated with acyl-HSL, the following measurements were performed every $12 \mathrm{~h}$ up to $96 \mathrm{~h}$. Figure 2 shows graphs which present changes in biofilm thickness after $96 \mathrm{~h}$ of growth. The biofilm treated with BHL is characterized by very fast growth up to $24 \mathrm{~h}$, after which fragments of the biofilm were dissociating BHL-treated biofilm, the thickest at every measurement point and had an average thickness of $13.73 \pm$ $3.58 \mu \mathrm{m}$. After $24 \mathrm{~h}$, the BHL biofilm biomass was 34 times higher than that of the control. Differences observed in the surface covered by biofilms were substantial after BHL treatment biofilm covered an area that was six times greater than that in the control. The volume of BHL-treated biofilm was 5.3 times greater, too. However, differences after $96 \mathrm{~h}$ were not so significant. Figure 3 shows that the control biofilm was not aggregated compared to biofilms formed under the influence of lactones, and especially BHL, DHL, and tDHL. In the presence of acyl-HSLs, high aggregation and increased amounts of mucus were noticed. Bacterial biofilms contain extracellular polymeric polysaccharides produced by bacterial cells grown in biofilm according to the method of Hamilton et al. (2003). The highest amount of polysaccharides was found in the biofilm produced after treatment with BHL $(p<0.002)$ and DHL $(p<0.0033)$, whereas treatment with OHL decreased the amount of exopolysaccharides in the biofilm.

\section{Discussion}

Biofilm is the most common mode of bacterial existence in the environment (Costerton et al. 1999). Biofilms forming on medical devices remain an unresolved medical problem (Maczynska et al. 2010). It is well-known that in Gramnegative bacteria signal molecules (quorum sensing) are an important factor in biofilm formation and development (Viana et al. 2009). The most common molecules involved in quorum sensing are acylated homoserine lactones (acylHSL). Their activity may influence many bacterial function, including biofilm formation. Proteus strains are known uropathogens capable of biofilm formation in catheters (Broomfield et al. 2009). In order to find out if Proteus strains are sensitive to a series of homoserine lactones, its effect on biofilms was tested. The influence of acylated homoserine lactones on mass, exopolysaccharide production, and structure of biofilms formed by P. mirabilis $\mathrm{O} 18$ and E. coli pCGJ strains was observed. Statistics showed that biofilms treated with BHL produced a higher amount of exopolysaccharides compared to controls. Biofilm growth on supplemented with BHL medium characterizes fast growing and sloughing after $36 \mathrm{~h}$ (Fig. 2b). Similar results gained by Rice and colleagues on their studies on Serratia 

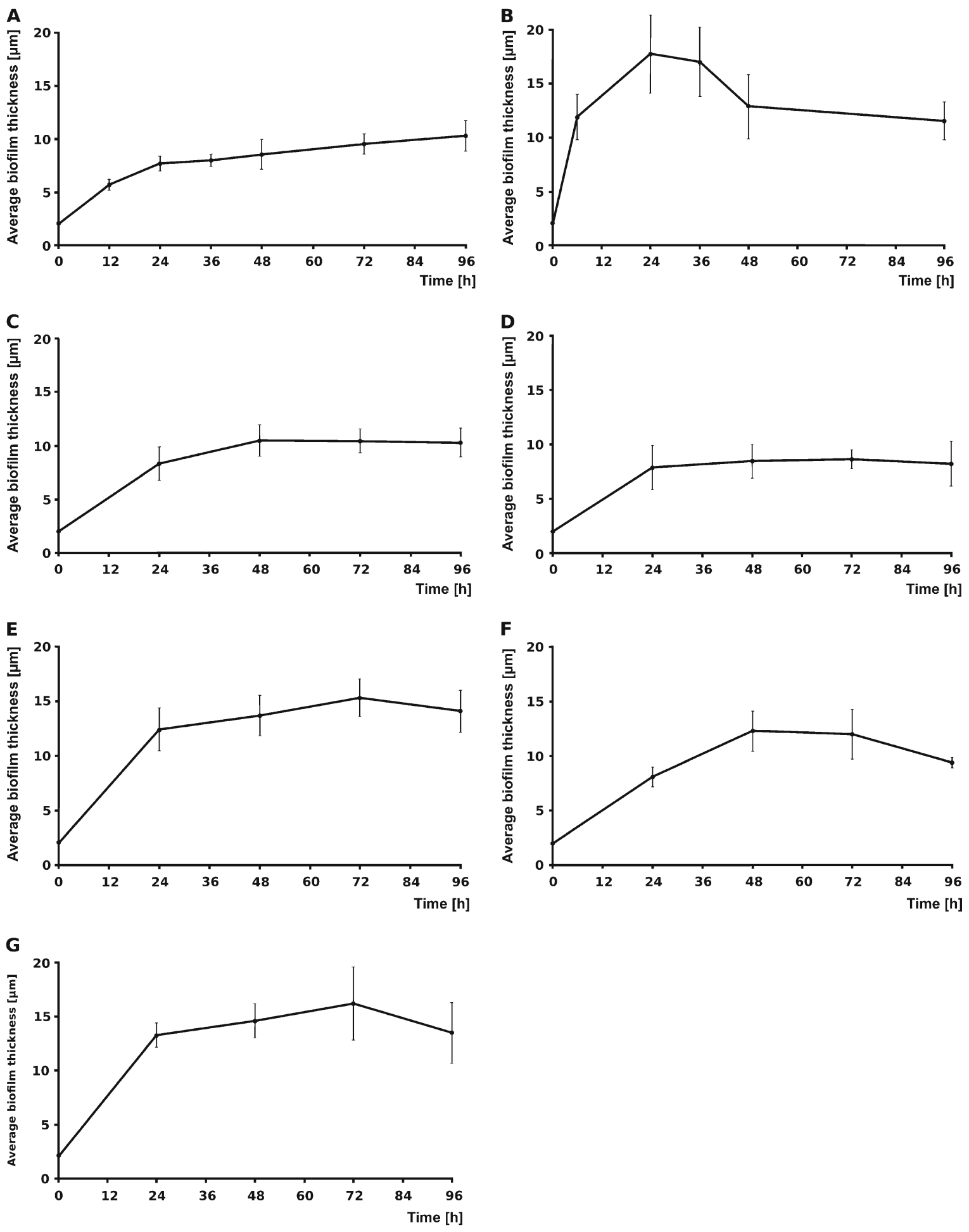

Fig. 2 The dynamics of biofilm formation for P. mirabilis $\mathrm{O} 18 \mathrm{pDsRed}_{2}$ under continuous flow conditions treated with $10 \mathrm{~nm}$ acyl-HSL. a Control, b BHL, c HHL, d OHL, e DHL, f dDHL, $\mathbf{g}$ tDHL. Error bars show standard deviation

marcescens suggest that biofilm formation is a dynamic process that is controlled by the quorum-sensing system (Rice et al. 2005). We observed significant differences between the amount of exopolysaccharides in biofilms formed by P. mirabilis $\mathrm{O} 18 \mathrm{pDsRed}{ }_{2}$ and in mixed biofilms
(P. mirabilis $\mathrm{O} 18 \mathrm{pDsRed}_{2}$, E. coli $\mathrm{pCGJ}$ ) after treatment with BHL $(p<0.05$, paired $t$ test $)$ and tDHL $(p<0.05$, paired $t$ test). From tested acylated homoserine lactones (BHL, HHL, OHL, DHL, dDHL, tDHL), BHL had a significant influence on the thickness, structure, and the amount of 
Fig. 3 Microphotographs of P. mirabilis $\mathrm{O} 18 \mathrm{pDsRed}_{2}$ biofilm formed under continuous flow conditions after: I, $48 \mathrm{~h}$ and II, $96 \mathrm{~h}$ of growth, treated with $10 \mathrm{~nm}: B$ BHL, $C$ HHL, $D$ OHL, $E$ DHL, $F$ dDHL, $G$ tDHL, and $A$ control P. mirabilis $\mathrm{O} 18$

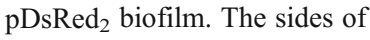
all squares are $230-\mu \mathrm{m}$ long
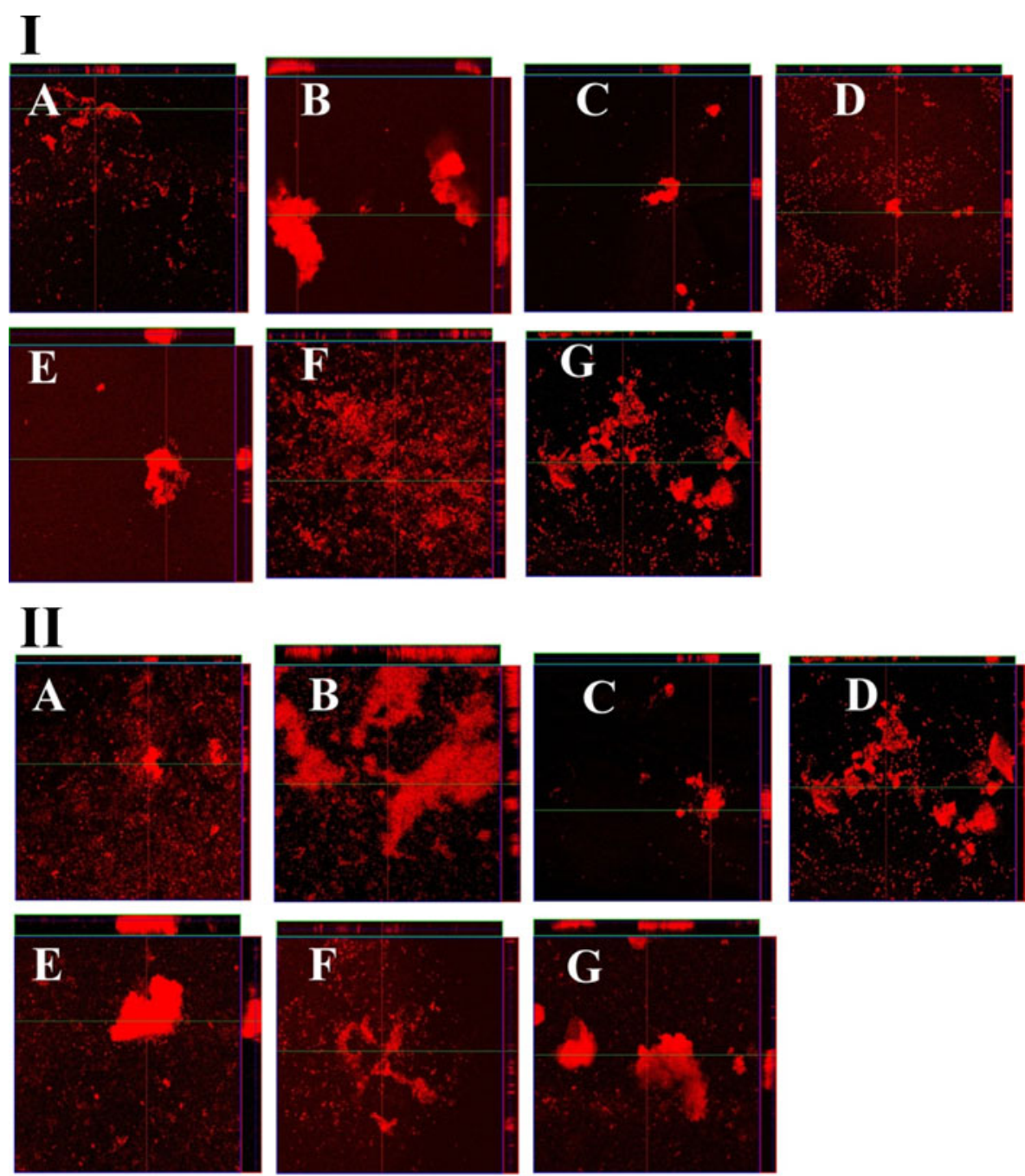

exopolysaccharides produced by biofilms formed by $P$. mirabilis $\mathrm{O} 18 \mathrm{pDsRed}_{2}$. Based on confocal microscopy observations, one may propose that acyl-HSLs influence biofilm formation and its structure. Under the influence of acyl-HSLs, the $E$. coli pCGJ biofilm significantly produced lower amounts of exopolysaccharides than the biofilm formed by P. mirabilis O18 $\mathrm{pDsRed}_{2}$ or mixed biofilm (P. mirabilis $\mathrm{O} 18 \mathrm{pDsRed}_{2}, E$. coli pCGJ). The different responses to different acyl-HSLs molecules by the two enteric strains may suggest that acylHSLs receptor protein molecules as well as promoter regions linked to acyl-HSLs differ, which may affect biofilm formation and development. In the presented work, we have found that Proteus strains can produce homoserine lactone rings, similarly to other Gram-negative bacteria. Furthermore, by genetic analysis we have shown the presence of the gene responsible for the production of quorum-sensing molecules. The identification of the luxS gene coding $S$-ribosylhomocysteine lyase responsible for AI-2 synthesis proves that $P$. mirabilis uses a quorumsensing communication system. Although luxS mutation does not disturb swarming motility (Schneider et al. 2002), it is possible that quorum sensing can interfere in the biofilm formation process as in the work of Viana et al. (2009). However, we have not identified types of acyl-HSLs produced by one Proteus strain tested. The presence and effects of acylHSLs are yet to be clarified. It is well-known that in enteric bacteria two quorum-sensing molecule systems are present (Kendall and Sperandio 2007). A system involving the AI-1 molecule base on acyl-HSL derivatives and engages luxIR genes. In our genetic studies, the presence of these genes in $P$. mirabilis $\mathrm{O} 18$ failed. However, we have shown that tested strain P. mirabilis $\mathrm{O} 18$ is sensitive to the examined BHL. That may suggest the presence of surface receptor proteins bindings BHL and changing the features of biofilm in stationary and continuous cultures. In the presented work, we identify gene lux $S$ coding AI-2 molecules synthase. The existence of this system in P. mirabilis O18 using molecules derivative of furanones was described by others (Schauder et al. 2001). In conclusion, the P. mirabilis $\mathrm{O} 18$ strain reacted and changed the population features based on the acyl-HSL produced by other Gram-negative bacteria as well as AI-2 molecules. The correlation and dependence of AI-1 and AI-2 systems remains to be discovered. 
Acknowledgments The study was supported by grant N N304 044639 from the National Science Centre. Some of the experiments were run on apparatus purchased with EU grant 2.2 Innovation Industry.

Open Access This article is distributed under the terms of the Creative Commons Attribution Noncommercial License which permits any noncommercial use, distribution, and reproduction in any medium, provided the original author(s) and source are credited.

\section{References}

Belas R, Schneider R, Melch M (1998) Characterization of Proteus mirabilis precocious swarming mutants: identification of rsbA, encoding a regulator of swarming behavior. J Bacteriol 180:61266139

Broomfield RJ, Morgan SD, Khan A, Stickler DJ (2009) Crystalline bacterial biofilm formation on urinary catheters by ureaseproducing urinary tract pathogens: a simple method of control. J Med Microbiol 58(Pt 10):1367-1375

Chromek M, Stankowska D, Dadfar E, Kaca W, Rabbani H, Brauner A (2005) Interleukin-8 response in cells from the human urinary tract induced by lipopolysaccharides of Proteus mirabilis $\mathrm{O} 3$ and O18. J Urol 173:1381-1384

Costerton JW, Stewart PS, Greenberg EP (1999) Bacterial biofilms: a common cause of persistent infections. Science 284:1318-1322

Gupta K, Sahm DF, Mayfield D, Stamm WE (2001) Antimicrobial resistance among uropathogens that cause community-acquired urinary tract infections in women: a nation wide analysis. Clin Infect Dis 33:89-94

Hamilton M, Heersink J, Buckingham-Meyer K, Goeres D (2003) The biofilm laboratory, step-by-step protocols for experimental design, analysis, and data interpretation. Cytergy Publishing, Bozeman

Henke JM, Bassler BL (2004) Bacterial social engagements. Trends Cell Biol 14:648-656

Heydorn A, Nielsen AT, Hentzer M, Sternberg C, Givskov M, Ersbøll BK, Molin S (2000) Quantification of biofilm structures by the novel computer program COMSTAT. Microbiology 146:23952407

Hryniewicz K, Szczypa K, Sulikowska A, Jankowski K, Betlejewska K, Hryniewicz W (2001) Antibiotic susceptibility of bacterial strains isolated from urinary tract infections in Poland. J Antimicrob Chemother 47:773-780

Kendall MM, Sperandio V (2007) Quorum sensing by enteric pathogens. Curr Opin Gastroenterol 23(1):10-15

Li H, Tanikawa T, Sato Y, Nakagawa Y, Matsuyama T (2005) Serratia marcescens gene required for surfactant serrawettin $\mathrm{W} 1$ production encodes putative aminolipid synthetase belonging to nonribosomal peptide synthetase family. Microbiol Immunol 49:303-310

Liaw SJ, Lai HC, Wang WB (2004) Modulation of swarming and virulence by fatty acids through the RsbA protein in Proteus mirabilis. Infect Immun 72:6836-6845

Lucas RL, Lostroh CP, DiRusso CC, Spector MP, Wanner BL, Lee CA (2000) Multiple factors independently regulate hilA and invasion gene expression in Salmonella enterica serovar Typhimurium. J Bacteriol 182:1872-1882

Maczynska B, Smutnicka D, Przondo-Mordarska A, Bartoszewicz M, Junka A, Janczura A, Nowicka J (2010) Biofilm formation by clinical Klebsiella strains expressing various types of adhesins on catheters made of different materials. Adv Clin Exp Med 19 (4):443-453

Nasser W, Reverchon S (2007) New insights into the regulatory mechanisms of the LuxR family of quorum sensing regulators. Anal Bioanal Chem 387:381-390

Rice SA, Koh KS, Queck SY, Labbate M, Lam KW, Kjelleberg S (2005) Biofilm formation and sloughing in Serratia marcescens are controlled by quorum sensing and nutrient cues. J Bacteriol 187(10):3477-3485

Schauder S, Shokat K, Surette MG, Bassler BL (2001) The LuxS family of bacterial autoinducers: biosynthesis of a novel quorum-sensing signal molecule. Mol Microbiol 41(2):463-476

Schneider R, Lockatell CV, Johnson D, Belas R (2002) Detection and mutation of a luxS-encoded autoinducer in Proteus mirabilis. Microbiology 148:773-782

Shaw PD, Ping G, Daly SL, Cha C, Cronan JE Jr, Rinehart KL, Farrand SK (1997) Detecting and characterizing $\mathrm{N}$-acyl-homoserine lactone signal molecules by thin-layer chromatography. Proc Natl Acad Sci USA 94:6036-6041

Sosa V, Zunino P (2009) Effect of Ibicella lutea on uropathogenic Proteus mirabilis growth, virulence, and biofilm formation. J Infect Dev Ctries 3(10):762-770

Soto MJ, Fernández-Pascual M, Sanjuan J, Olivares J (2002) A fadD mutant of Sinorhizobium meliloti shows multicellular swarming migration and is impaired in nodulation efficiency on alfalfa roots. Mol Microbiol 43:371-382

Stankowska D, Kwinkowski M, Kaca W (2008) Quantification of Proteus mirabilis virulence factors and modulation by acylated homoserine lactones. J Microbiol Immunol Infect 41:243-253

Stickler D, Young R, Jones G, Sabbuba N, Morris N (2003) Why are Foley catheters so vulnerable to encrustation and blockage by crystalline bacterial biofilm? Urol Res 31:306-311

Viana ES, Campos MEM, Ponce AR, Mantovani HC, Vanetti MCD (2009) Biofilm formation and acyl homoserine lactone production in Hafnia alvei isolated from raw milk. Biol Res 42:427-436

Wang LH, He Y, Gao Y, Wu JE, Dong YH, He C, Wang SX, Weng LX, Xu JL, Tay L, Fang RX, Zhang LH (2004) A bacterial cell-cell communication signal with cross-kingdom structural analogues. Mol Microbiol 51:903-912

Wielbo J, Golus J, Marek-Kozaczuk M, Skorupska A (2010) Symbiosis-stage associated alterations in quorum sensing autoinducer molecules biosynthesis in Sinorhizobium meliloti. Plant Soil 329:399-410

Williams P, Camara M, Hardman A, Swift S, Milton D, Hope VJ, Winzer K, Middleton B, Pritchard DI, Bycroft BW (2000) Quorum sensing and the population-dependent control of virulence. Philos Trans R Soc Lond B Biol Sci 355:667-680

Zhu H, Shen YL, Wei DZ, Zhu JW (2008) A novel quorum sensing system co-regulated by chromosome- and plasmid-encoded genes in Serratia marcescens H30. Mol Cell Biochem 319:87-90 